\title{
Global patterns of bioturbation intensity and mixed depth of marine soft sediments
}

\author{
L. R. Teal ${ }^{1,2, *}$, M. T. Bulling ${ }^{1,3}$, E. R. Parker $^{2}$, M. Solan ${ }^{1}$ \\ ${ }^{1}$ Oceanlab, University of Aberdeen, Main Street, Newburgh, Aberdeenshire AB41 6AA, UK \\ ${ }^{2}$ CEFAS, Pakefield Road, Lowestoft, Suffolk NR33 0HT, UK \\ ${ }^{3}$ University of York, Environmental Department, Heslington, York YO10 5DD, UK
}

\begin{abstract}
The importance of bioturbation in mediating biogeochemical processes in the upper centimetres of oceanic sediments provides a compelling reason for wanting to quantify in situ rates of bioturbation. Whilst several approaches can be used for estimating the rate and extent of bioturbation, most often it is characterized by calculating an intensity coefficient $\left(D_{\mathrm{b}}\right)$ and/or a mixed layer depth $(L)$. Using measures of $D_{\mathrm{b}}(\mathrm{n}=447)$ and $L(\mathrm{n}=784)$ collated largely from peer-reviewed literature, we have assembled a global database and examined patterns of both $L$ and $D_{\mathrm{b}}$. At the broadest level, this database reveals that there are considerable gaps in our knowledge of bioturbation for all major oceans other than the North Atlantic, and almost universally for the deep ocean. Similarly, there is an appreciable bias towards observations in the Northern Hemisphere, particularly along the coastal regions of North America and Europe. For the assembled dataset, we find large discrepancies in estimations of $L$ and $D_{\mathrm{b}}$ that reflect differences in boundary conditions and reaction properties of the methods used. Tracers with longer half-lives tend to give lower $D_{\mathrm{b}}$ estimates and deeper mixing depths than tracers with shorter half-lives. Estimates of $L$ based on sediment profile imaging are significantly lower than estimates based on tracer methods. Estimations of $L$, but not $D_{\mathrm{b}}$, differ between biogeographical realms at the global level and, at least for the Temperate Northern Atlantic realm, also at the regional level. There are significant effects of season irrespective of location, with higher activities $\left(D_{\mathrm{b}}\right)$ observed during summer and deeper mixing depths $(L)$ observed during autumn. Our evaluation demonstrates that we have reasonable estimates of bioturbation for only a limited set of conditions and regions of the world. For these data, and based on a conservative global mean $( \pm \mathrm{SD}) L$ of $5.75 \pm 5.67 \mathrm{~cm}(\mathrm{n}=791)$, we calculate the global volume of bioturbated sediment to be $>20700 \mathrm{~km}^{3}$. Whilst it is clear that the role of benthic invertebrates in mediating global ecosystem processes is substantial, the level of uncertainty at the regional level is unacceptably high for much of the globe.
\end{abstract}

KEY WORDS: Bioturbation - Sediment mixed depth - Bioturbation coefficient - Global analysis · Tracer $\cdot$ Sediment profile imaging

\section{INTRODUCTION}

The seabed is the most extensive habitat on the planet, occupying $>75 \%$ of the Earth's surface. Most marine sediments are cohesive muds that are replete with complex biogeochemical cycles, which are critical for the marine ecosystem. Benthic macrofauna bioturbate and bioirrigate the upper centimetres of marine sediments, significantly increasing the depth of the mixed layer, the recycling of nutrients, and the flux of materials from the sediment to the water column. Accurate measurements of bioturbation rates are crucial in determining how faunal-induced fluid and particle redistribution affects the properties of the sediment profile. Given the vast area of marine sediments across the globe and the importance of bioturbators in mediating ecosystem processes, there are numerous studies measuring bioturbation values worldwide. To- 
gether, these form a valuable repository of information on global patterns of bioturbation intensity and the mixed depth of marine soft sediments (see e.g. Boudreau 1994, 1998, Middelburg et al. 1997).

Studies investigating the rate and extent of bioturbation have generally adopted modelling techniques that allow the distribution and exchange rates of pore water solutes, or sediment particles, across the sedimentwater interface to be quantified and compared. Bioturbation is characterized numerically by determining a mixed layer depth $(L)$, over which sediment mixing most frequently occurs, and/or a bioturbation coefficient $\left(D_{\mathrm{b}}\right)$ (for review, see Meysman et al. 2003). $D_{\mathrm{b}}$ is defined as the rate at which the variance of particle location changes over time, where the variance is a measure of the spread of particles in a tracer profile and is proportional to the velocity of the diffusing particle (Crank 1975), thus providing a convenient descriptor of the intensity of bioturbation. Both $L$ and $D_{\mathrm{b}}$ can be determined by measuring the vertical distribution of a tracer through the sediment profile. Tracers commonly used for bioturbation experiments include naturally occurring, particle reactive radionuclides and artificial tracers such as glass beads, fluorescent sediment particles (luminophores), metal-doped sediment and isotopically labelled algae (Mahaut \& Graf 1987, Wheatcroft et al. 1994, Blair et al. 1996, Gerino et al. 1998, Sandnes et al. 2000, Berg et al. 2001, Green et al. 2002, Forster et al. 2003). Incorporation of the tracer into the sediment by faunal activity results in a vertical tracer profile that is either: (1) smooth and exponential in decline, in which case faunal-mediated particle movements approximate diffusional mixing, or (2) more complex, resulting from discrete burrowing events, in which case particles are displaced by the fauna in a series of 'non-local' movements. Mathematical models appropriate to the form of the tracer profile are applied, and a $D_{\mathrm{b}}$ coefficient can be estimated (for an overview, see Meysman et al. 2003, 2008, this Theme Section). $L$ can also be determined from tracer profiles, or, when using alternative methods such as sediment profile imaging (SPI; Rhoads \& Cande 1971), can be measured directly from the sediment profile.

Despite methodological differences (Gerino et al. 1998), some analyses of published $D_{\mathrm{b}}$ and $L$ values have been used to determine empirical relationships between parameters used in diagenetic models and water depth (Boudreau 1994, 1998, Middelburg et al. 1997). Such empirical relationships can enable predictions to be made about biogeochemical rates and processes in oceanic sediments where data are still limited or absent. In a rudimentary analysis of $>200$ datapoints, for example, Boudreau (1994) found a significant correlation between $D_{\mathrm{b}}$ and sedimentation rate $(\omega)$, both of which decrease with increasing water depth (Middelburg et al. 1997). Conversely, no apparent relationships between $L$ and $\omega$ or $L$ and water depth were found. In fact, $L$ exhibited a well-defined world-wide mean $( \pm \mathrm{SD})$ of 9.8 $\pm 4.5 \mathrm{~cm}$ (Boudreau 1994), which was later shown to result from the feedback between the food dependence of bioturbation and the decay of that resource (Trauth et al. 1997, Boudreau 1998, Smith \& Rabouille 2002). In this case, the independence of $L$ would indicate that considerable confidence can be placed in using an average $L$ in sediment modelling (Boudreau 1994), although we recognize that the factors influencing $L$ are likely to be numerous and interact with one another.

This contribution builds on that of Boudreau (1994, 1998) by extending the database of $L$ and $D_{\mathrm{b}}$. Our objectives were to: (1) examine the relationship between measured estimates of bioturbation and the method of determination, (2) determine the influence of season, water depth and location on $D_{\mathrm{b}}$ and $L_{\mathrm{r}}$ (3) identify areas of high and low $D_{\mathrm{b}}$ and $L$, (4) highlight regions or benthic habitats that have been poorly researched, and (5) refine the global estimate of bioturbated sediment. In so doing, we wish to summarise the present knowledge of bioturbation at the global level and, after taking into account biases in the data, recommend areas of future research.

\section{METHODS}

Global database. Global data on $L$ and $D_{\mathrm{b}}$ were collated from peer-reviewed literature. Data were retrieved from the 'ISI Web of Knowledge' using the 'Science Citation Index Expanded' and 'Social Sciences Citation Index' databases. A 'general search' using the search term bioturbation in the titles and key words of all document types, in all languages, was performed for the publication years 1970 to 2006. All published sources were manually searched for values of $L$ and/or $D_{\mathrm{b}}$, and, where available, additional information was gathered on the geographical position of the study (latitude, longitude), water depth, sedimentation rates $(\omega)$, type of tracer used (hereafter method) and month of year the measurement was taken. Additional $D_{\mathrm{b}}$ and $L$ values were added from the publications cited in Boudreau (1994), and further estimates of $L$ were obtained from the sediment profile imaging literature. Much of the latter includes monitoring studies that document localized benthic impacts. As our focus was to determine representative estimates of bioturbation, only reference sites furthest away from any anthropogenic impact (as defined by the study authors), or sites acknowledged as having no discernable anthropogenic impact, were used. In addition, we determined additional values for $L$ from previously unpublished SPI surveys $(\mathrm{n}=31$; for sources, see 
'Acknowledgements'). In SPI images, the depth of $L$ is delineated using the vertical colour transition (from brown to olive green/black) that occurs within the sediment profile (Fenchel 1969, Lyle 1983). This coloration is dictated by the redox state (ferrous or ferric) of the dominant electron acceptor iron (Lovley \& Phillips 1986), such that regions of high reflectance (brown) in an image represent the oxidised bioturbated sediment and can be delineated using standard threshold analysis. For all unpublished SPI surveys, $L$ was determined using a custom-made, semi-automated macro that runs within ImageJ (Version 1.38), a Java-based public domain program developed at the USA National Institutes of Health (available at http:// rsb.info.nih.gov/ij/index.html). Including all sources of information, the total database included $>2000$ studies. After eliminating publications that lacked the data required and including data from studies that investigated multiple locations, the refined database included 791 individual values of $L$ and 454 individual values of $D_{\mathrm{b}}$ from 130 publications and the additional SPI analyses.

Generation of a global map. All points (latitude and longitude) were plotted on a global map (Fig. 1) using ArcView GIS (v3.3). When the precise location of a study was not provided, latitude and longitude coordinates were estimated from the available in- formation reported in each study using Google Earth (http://earth.google.com/). To account for regional differences in environmental conditions, Bailey's oceanic regions (Bailey 1998) and Spalding's coastal regions (Spalding et al. 2007) were combined to ensure complete global coverage. Within these regions, there are 2 oceanic levels (domains and ecoregions) and 3 coastal levels (realms, provinces and ecoregions). Using GIS, each datapoint was linked to its corresponding domain and ocean ecoregion or, in coastal areas, the corresponding realm, province and coastal ecoregion.

An estimate of the area of the global ocean floor was generated using ETOPO2v2 (2006; available from the US National Geophysical Data Center www.ngdc. noaa.gov/). Several digital databases of seafloor elevations contribute to this database on a 2' latitudelongitude grid ( $1^{\prime}$ of latitude $=1 \mathrm{n}$ mile $=1852 \mathrm{~m}$ ). The resolution of the gridded data varies from true 2 ' intervals for the Atlantic, Pacific and Indian Ocean floors and all land masses to $5^{\prime}$ for the Arctic Ocean floor.

Statistical analysis. The inherent biases in the data (Table 1) made the statistical analyses potentially imbalanced, with some independent variables poorly represented. We therefore removed from each analysis all independent variables with $<5$ datapoints. Sedimentation rate was excluded from the analysis, as few studies included estimates. As a significant portion of

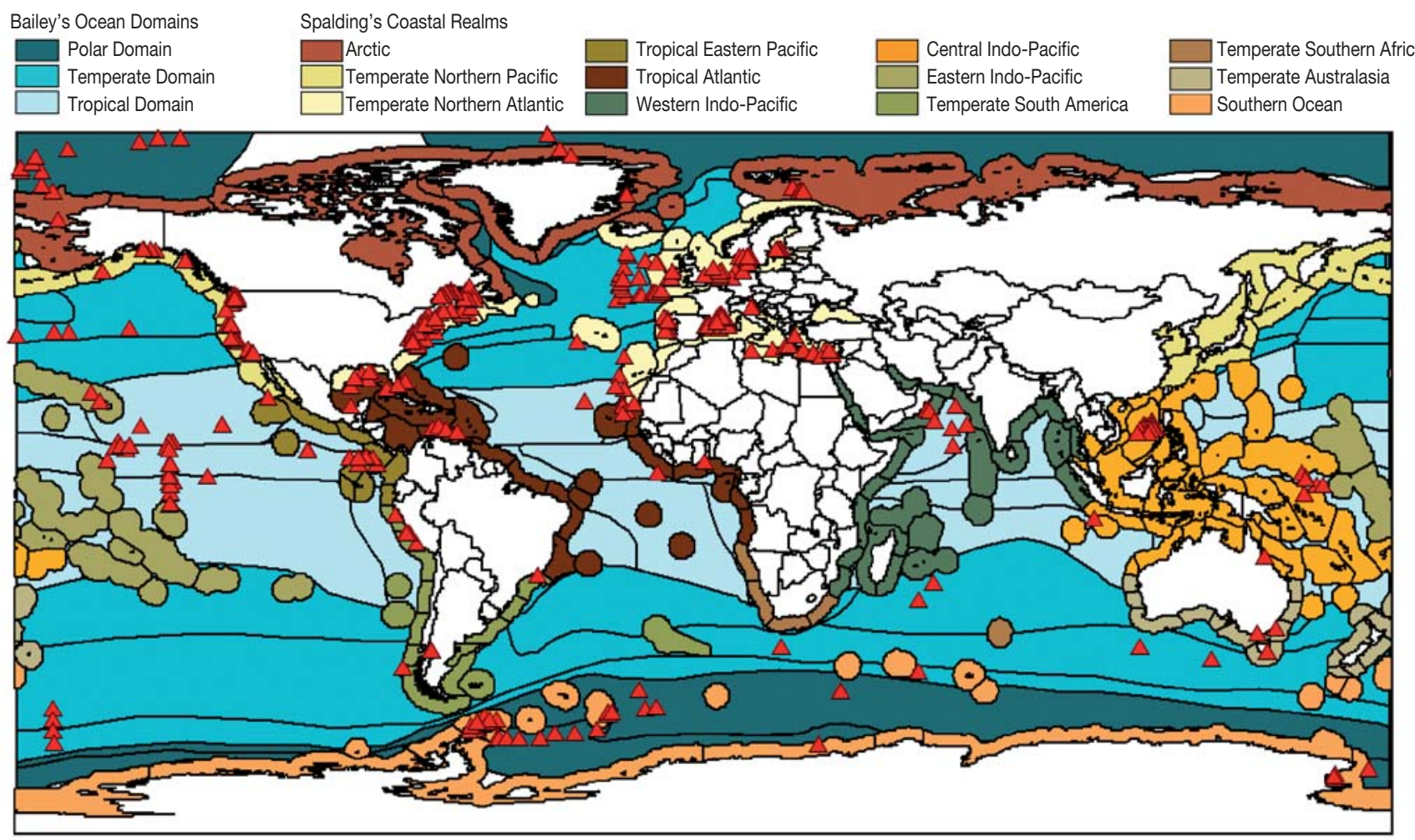

Fig. 1. World map showing ocean domains and coastal realms (coloured areas), ocean and coastal ecoregions (black borders), and locations where $D_{\mathrm{b}}$ and/or $L$ values have been measured (red triangles) 
Table 1. Summary of the bioturbation database. Number of observations for mixing depth $(L)$ and mixing intensity $\left(D_{\mathrm{b}}\right)$, by Bailey's ocean domains and Spalding's coastal realms (see Fig. 1), as well as by method. Methods with $<10$ datapoints $\left({ }^{134} \mathrm{Cs},{ }^{137} \mathrm{Cs},{ }^{18} \mathrm{O},{ }^{32} \mathrm{Si},{ }^{7} \mathrm{Be},{ }^{226,228} \mathrm{Ra}\right.$, tektites, organic $\mathrm{C}$, glass beads, X-ray) are included in 'Other'. SPI: sediment profile imaging

\begin{tabular}{lrr|}
\hline & $L$ & $D_{\mathrm{b}}$ \\
\hline Region & & \\
Polar Domain & 26 & 16 \\
Temperate Domain & 31 & 32 \\
Tropical Domain & 33 & 63 \\
Arctic & 3 & 2 \\
Temp. N. Pacific & 87 & 97 \\
Temp. N. Atlantic & 497 & 170 \\
Trop. E. Pacific & - & 8 \\
Trop. Atlantic & 33 & 29 \\
W. Indo-Pacific & 15 & 12 \\
Central Indo-Pacific & 24 & 1 \\
E. Indo-Pacific & 3 & 2 \\
Temp. S. America & 14 & 10 \\
Temp. S. Africa & - & - \\
Temp. Australasia & 3 & 1 \\
Southern Ocean & 16 & 8 \\
Method & & \\
${ }^{14}$ C & 15 & 275 \\
${ }^{210}$ Pb & 307 & 102 \\
${ }^{234}$ Th & 36 & 18 \\
Chl a & 1 & 16 \\
${ }^{239}$ 240 Pu & 12 & 13 \\
Luminophores & 13 & 1 \\
SPI & 358 & 24 \\
Colour & 19 & \\
Other & 27 & \\
\hline
\end{tabular}

datapoints (32\% in the case of $D_{\mathrm{b}}, 59 \%$ in the case of $L_{\text {; }}$ Table 1) represented the Temperate Northern Atlantic realm, we performed a global analysis on all data followed by an analysis using only data from the Temperate Northern Atlantic realm. At the global level, the largest divisions (Spalding's realms + Bailey's domains, hereafter referred to collectively as 'regions') were used to ensure sufficient data were present to enable comparisons. For analyses within the regional level, we adopted Spalding's ecoregions (hereafter referred to as 'subregions'). Latitude and longitude were potential independent variables, but were excluded from the analyses because: (1) there was distinct clustering in the distribution of the data; (2) they do not necessarily describe a set gradient of environmental conditions; and (3) such clines are not continuous, as they are disrupted by landmasses and oceanographic features, such as large-scale current flows. Water depth was treated as a continuous independent variable. Method included 18 levels $\left({ }^{210} \mathrm{~Pb},{ }^{14} \mathrm{C},{ }^{234} \mathrm{Th},{ }^{239,}{ }^{240} \mathrm{Pu},{ }^{134} \mathrm{Cs}\right.$, ${ }^{137} \mathrm{Cs},{ }^{18} \mathrm{O},{ }^{32} \mathrm{Si},{ }^{7} \mathrm{Be},{ }^{226,228} \mathrm{Ra}$, Tektites, organic $\mathrm{C}$, chl a, glass beads, luminophores, colour, X-ray, SPI) and was treated as a nominal independent variable. As the distribution of data between methods was uneven (Table 1), methods with $<10$ observations were grouped together into a separate category (Other) in order to maximize the number of data available for the model, but this grouping was not compared directly to specific methods.

As our analyses include data from both the Northern and Southern Hemispheres, where calendar months do not correspond to the same season, the seasonal offset was corrected by classifying each study into 1 of 4 seasons (spring, summer, autumn and winter). Spring included studies that took place between April and June in the Northern Hemisphere (NH) or October and December in the Southern Hemisphere (SH). Summer included studies that took place during July to September $(\mathrm{NH})$ or January to March $(\mathrm{SH})$; autumn, during October to December $(\mathrm{NH})$ or April to June $(\mathrm{SH})$; and winter, during January to March $(\mathrm{NH})$ or July to September (SH). Due to latitudinal variations in seasonal timing, the scheme is not representative of any specific location.

In the global and Temperate Northern Atlantic realms, both dependent variables ( $L$ and $D_{\mathrm{b}}$ ) followed a highly skewed distribution with many small values. We assessed the use of generalized linear modelling using a Poisson or quasi-Poisson link, but highly skewed distributions remained in the residuals due to strong over-dispersion. We therefore cube roottransformed $L$ and $D_{\mathrm{b}}$ (less severe transformations were insufficient). For both the global and the Temperate Northern Atlantic realm analysis, the first step was a linear regression model for both $L$ and $D_{\mathrm{b}}$, with season and method as nominal independent variables, and water depth as a continuous independent variable. We tested for potential regional (or, within the Temperate Northern Atlantic realm models, subregional) effects by producing a linear mixed model with random regional effects. Comparison with the original linear model was carried out using the likelihood ratio test. If the random effect was found to be significant at the 0.05 level, the random structure in the model was retained. At this stage, for some of the models, the diagnostic residual plots indicated heteroscedasticity due to the inherent heterogeneity of variance within independent variables. If this was the case, we produced models using the generalized least squares (GLS) extension. GLS allows the introduction of a range of variance-covariate structures (see Table 5.1 in Pinheiro \& Bates 2000) that model the variance structure. These models were compared with the equivalent model without the GLS extension using Akaike's information criterion (AIC) and examination of plots of residuals versus fitted values. The model with the most-appropriate random structure was then 

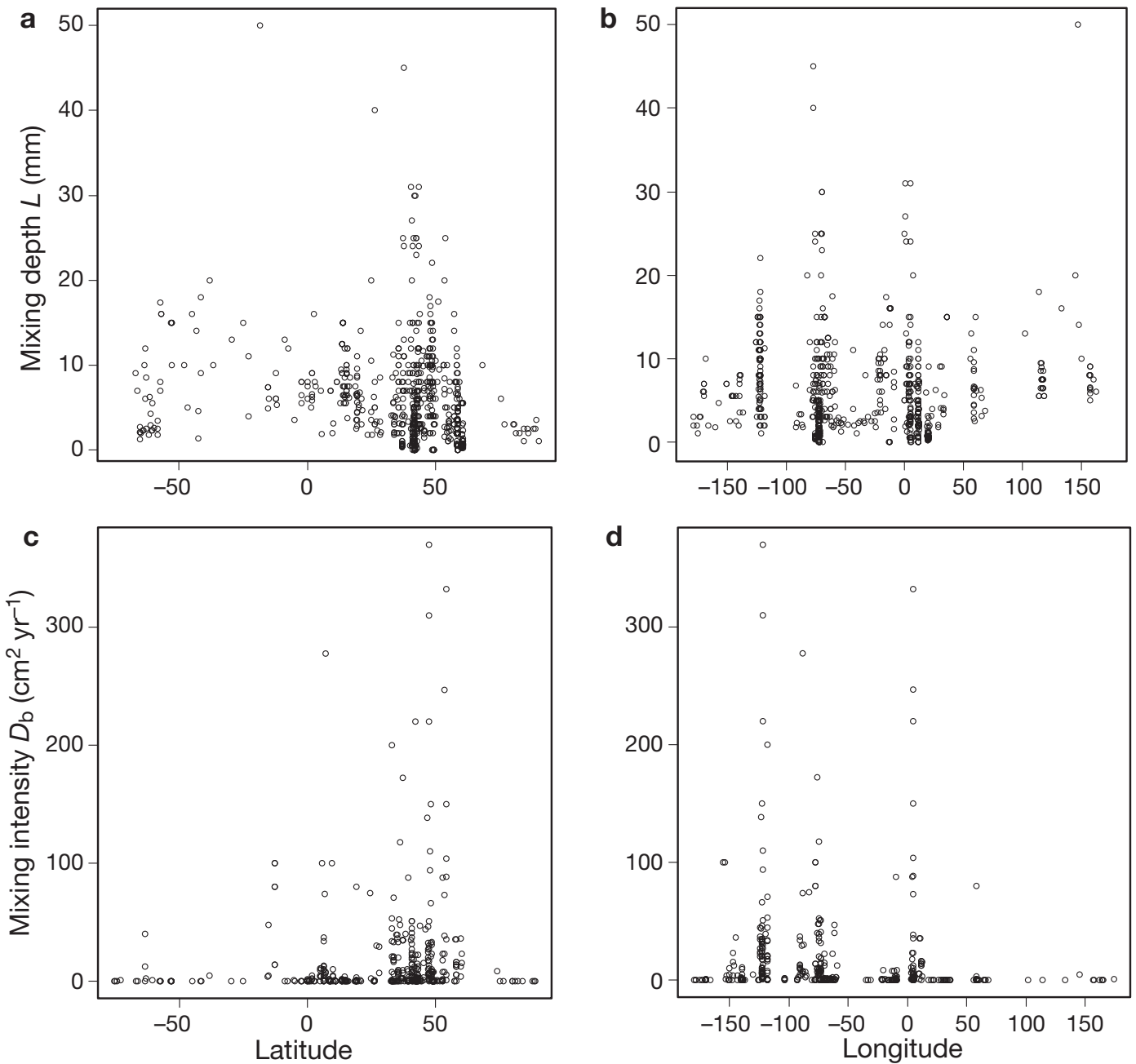

Fig. 2. Global patterns of bioturbation expressed as $(\mathrm{a}, \mathrm{b})$ mixing depth $(L)$ and $(\mathrm{c}, \mathrm{d})$ mixing intensity $\left(D_{\mathrm{b}}\right)$ for $(\mathrm{a}, \mathrm{c})$ latitude and $(\mathrm{b}, \mathrm{d})$ longitude

used as a starting point for determining the mostappropriate fixed structure. This was done by applying a backward selection process using the likelihood ratio test obtained by maximum likelihood estimation. The numerical output of the minimal adequate model was obtained using restricted maximum likelihood (REML) (Faraway 2006, West et al. 2007). All analyses were performed using the 'nlme' package (v3.1; Pinheiro et al. 2006) in the ' $R$ ' statistical and programming environment (R Development Core Team 2005).

\section{RESULTS}

The database included 791 measurements of $L$ and 454 measurements of $D_{\mathrm{b}}$. The greater numbers of mixing depth data were largely attributable to the inclusion of SPI, which generally does not provide an estimate of $D_{\mathrm{b}}$ (but see Solan et al. 2004). At the broadest level, the global coverage of bioturbation estimates was reasonable, but highly clustered (Fig. 1). The data revealed a strong bias towards the Northern Hemisphere and, in particular, coastal regions thereof. Remote locations such as the Central Pacific and Antarctic were represented by a limited number of studies often based on a single cruise or research campaign (e.g. ANDEEP; Diaz 2004, Howe et al. 2004, 2007). In terms of latitude and longitude, data were available from $89.98^{\circ} \mathrm{N}$ to $75.20^{\circ} \mathrm{S}$ and from $174.00^{\circ} \mathrm{E}$ to $179.76^{\circ} \mathrm{W}$. Over $88 \%$ of the data, however, emanated from studies in the Northern Hemisphere, particularly along the coasts of North America and Europe (Figs. 1 \& 2). No obvious patterns or trends were observed in either $L$ or $D_{\mathrm{b}}$ from north to south (Fig. 2a,c) or from east to west (Fig. 2b,d).

For water depth, estimates of bioturbation ( $L$ and $D_{\mathrm{b}}$ ) ranged from the intertidal zone $(0 \mathrm{~m}, \mathrm{n}=8)$ down to $5654 \mathrm{~m}$ (Yang et al. 1986), although the data were highly skewed towards shallower waters (mean $\pm \mathrm{SD}=$ $1133 \pm 1630 \mathrm{~m}$, median $=100 \mathrm{~m}, \mathrm{n}=917)$. Most esti- 
mates of bioturbation ( $L$ and $D_{\mathrm{b}}$ ) were from the shelf $(<200 \mathrm{~m})$ or coastal regions $(\mathrm{n}=510)$, with fewer from bathyal $(\mathrm{n}=174)$ or abyssal $(\mathrm{n}=223)$ depths. No estimates of hadal bioturbation were available. Seasonal information was difficult to collate as observation dates were missing in $47 \%$ of the studies. Of those studies that did include dates, $79 \%$ took place in spring or summer.

Regional and methodological biases within the data are shown in Table 1. For $L$, regions that were not well represented $(\mathrm{n}<5)$ include the Arctic, Eastern IndoPacific and Temperate Australasia. Measurements were missing for the Tropical Eastern Pacific. The vast majority of $L$ data was from the Temperate Northern Atlantic realm, which includes the North American east coast and European coastal waters. This was reflected in the large range of $L$ values at approximately $50^{\circ} \mathrm{N}, 0^{\circ} \mathrm{W}$ and $75^{\circ} \mathrm{W}$ (Fig. 2a,b).

Although slightly less pronounced, a similar pattern in the distribution of data existed for $D_{\mathrm{b}}$. As with $L$, there were no obvious patterns or trends with latitude or longitude, and the large range of $D_{\mathrm{b}}$ values around $50^{\circ} \mathrm{N}$, and in the Western Hemisphere, corresponded to where most data have been collected. Although $D_{\mathrm{b}}$ values were present for all regions, data were sparse $(\mathrm{n}<5)$ in the Arctic, Central Indo-Pacific, Eastern IndoPacific and Temperate Australasia. Whereas SPI and ${ }^{210} \mathrm{~Pb}$ were by far the most common methods used to measure $L$ (Table 1), comprising 45 and $39 \%$ of the mixing depth data, respectively, most $D_{\mathrm{b}}$ values were calculated from models on ${ }^{210} \mathrm{~Pb}(61 \%)$ and ${ }^{234} \mathrm{Th}$ $(22 \%)$ tracer profiles.

\section{Global analysis}

\section{Mixing depth $(L)$}

The simplest model adequate for the analysis of mixing depth $(\mathrm{n}=300)$ was a linear mixed effects model incorporating 3 single terms (method, season and water depth). The maximal subset of data included 4 levels of method $\left({ }^{210} \mathrm{~Pb},{ }^{234} \mathrm{Th}\right.$, luminophores, SPI) and all 4 seasons. Region was included as a random factor as it contributed significantly to the model (L-ratio = 82.06, $\mathrm{df}=1, \mathrm{p}<0.0001$ ). The variance-covariate terms were season and water depth. Method had the greatest influence on $L$ (L-ratio $=94.69, \mathrm{df}=4, \mathrm{p}<0.0001$ ), followed by season (L-ratio $=31.10, \mathrm{df}=3, \mathrm{p}<0.0001$ ) and water depth (L-ratio $=3.94, \mathrm{df}=1, \mathrm{p}=0.047$ ), which was only marginally significant. The data were not strong enough to investigate interactions between the single terms.

The depth of $L$ was dependent on the type of tracer used, a finding consistent with that of others (e.g.
Gerino et al. 1998). The 2 most-common methods used to calculate $L$ were ${ }^{210} \mathrm{~Pb}$ tracers and SPI, although values of $L$ were significantly lower when estimated with SPI (coefficient $=-0.757, \mathrm{df}=286, \mathrm{p}<0.0001$; Fig. 3a). Estimates of $L$ based on ${ }^{234} \mathrm{Th}$ were also significantly lower than those based on ${ }^{210} \mathrm{~Pb}$ (coefficient $=-0.528$, $\mathrm{df}=286, \mathrm{p}=0.0001)$. Luminophore tracers provided estimates of $L$ that were marginally lower than those based on ${ }^{210} \mathrm{~Pb}$ (coefficient $=-0.389, \mathrm{df}=286, \mathrm{p}=0.047$ ) and marginally higher than those based on ${ }^{234} \mathrm{Th}$ (coefficient $=0.139, \mathrm{df}=286, \mathrm{p}=0.534$ ) and SPI (coefficient $=0.368, \mathrm{df}=286, \mathrm{p}=0.050$ ).

The timing of each bioturbation study with respect to season was also influential in determining the depth of $L$. Mixing depths were greatest in the autumn relative to all other seasons (Fig. 3b, p $<0.001$ in all cases). Summer values of $L$ were shallower than those determined in the spring (coefficient $=-0.133, \mathrm{df}=286, \mathrm{p}=$ 0.001). We found no evidence that mixing depths determined in winter were different to any other season; however, the low numbers of data $(n=15)$ for winter made this conclusion tentative.

In contrast to the findings of Boudreau (1994), we found that water depth had a significant and positive effect on mixing depth (coefficient $=9.25 \times 10^{-5}, \mathrm{df}=$ $286, p=0.0498$ ). However, the coefficient is so small that it is unlikely to be ecologically relevant.

\section{Bioturbation intensity $\left(D_{\mathrm{b}}\right)$}

The minimum adequate model for the analysis of $D_{\mathrm{b}}$ $(n=140)$ was a linear regression with a GLS extension incorporating 3 single terms (method, season and water depth). The maximal subset of data included 4 levels of method $\left({ }^{210} \mathrm{~Pb},{ }^{234} \mathrm{Th}\right.$, chl $a$, luminophores) and all 4 seasons. There was no significant effect of region
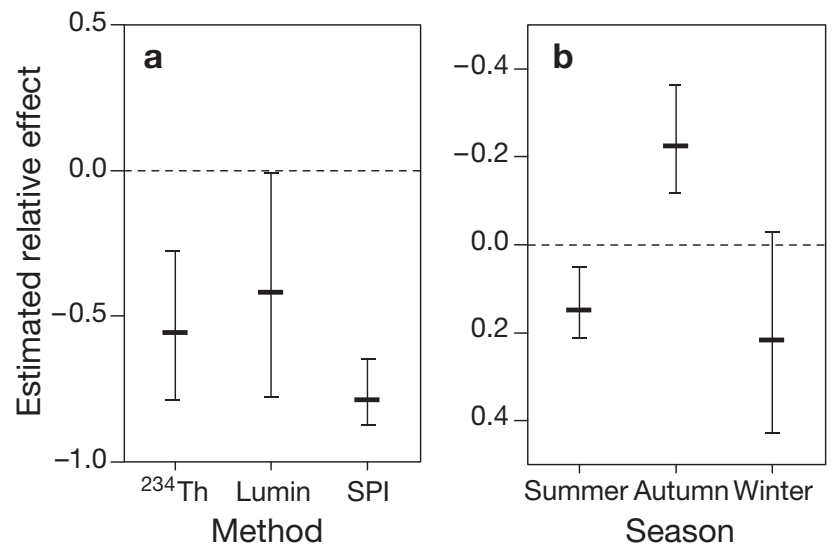

Fig. 3. Estimated relative effect of (a) method and (b) season for the global analysis of mixing depth $(L) ;$ (a) relative to ${ }^{210} \mathrm{~Pb}$ (dashed line); (b) relative to spring (dashed line). Error bars show $95 \%$ CI. Lumin: luminophores 
as a random factor (L-ratio $=0.53, \mathrm{df}=1, \mathrm{p}=0.466$ ), so it was removed from the model. Season was the only necessary variance-covariate term. Method had the greatest influence on $D_{\mathrm{b}}$ (L-ratio $=64.747$, df $=3$, $\mathrm{p}<$ 0.0001 ), followed by season (L-ratio $=18.12$, $\mathrm{df}=3, \mathrm{p}<$ 0.001 ) and water depth (L-ratio $=15.50$, df $=1, \mathrm{p}<$ 0.0001). As for $L$, the data for $D_{\mathrm{b}}$ was not strong enough to investigate interactions between the single terms.

Estimates of $D_{\mathrm{b}}$ determined using ${ }^{210} \mathrm{~Pb}$ were lower than those based on ${ }^{234} \mathrm{Th}$ (coefficient $=-0.735$, df $=$ 139, $\mathrm{p}<0.0001$ ), chl a (coefficient $=-1.391$, df $=139$, $\mathrm{p}<0.0001$ ), or luminophores (coefficient $=-1.277$, df $=$ 139, $\mathrm{p}=0.0001$ ) (Fig. 4a). Of the latter 3 methods, ${ }^{234}$ Th-based $D_{\mathrm{b}}$ values were significantly lower than those based on chl a (coefficient $=-0.656$, df $=139$, p < 0.001), whilst luminophore-based $D_{\mathrm{b}}$ values were equivalent to those estimated using ${ }^{234} \mathrm{Th}$ (coefficient $=$ -0.542 , df $=139, \mathrm{p}=0.095$ ) and chlorophyll a (coefficient $=0.1134, \mathrm{df}=139, \mathrm{p}=0.735$ ).

Whereas the greatest depth of $L$ occurred in the autumn, the highest $D_{\mathrm{b}}$ value was recorded in summer, declining through autumn, winter and spring (Fig. 4b). Both summer and autumn $D_{\mathrm{b}}$ values were significantly higher than values obtained in the spring (coefficient $=$ 0.664, $\mathrm{df}=139, \mathrm{p}<0.0001$ and coefficient $=0.412, \mathrm{df}=$ $139, \mathrm{p}=0.005$, respectively). As with $L$, we found no evidence that $D_{\mathrm{b}}$ values were higher in the winter; this was also most likely due to the low quantity of data ( $\mathrm{n}=$ 17) available.

The values for $D_{\mathrm{b}}$ were significantly and negatively affected by water depth (coefficient $=-1.61 \times 10^{-4}, \mathrm{df}=$ 139, $\mathrm{p}<0.0001)$. However, as with $L$, the coefficient was so small that it was likely to be ecologically irrelevant; the effect of water depth over the maximum depth range in the ocean $(\sim 11000 \mathrm{~m})$ would amount to $<1.8 \mathrm{~cm}^{2} \mathrm{yr}^{-1}$.
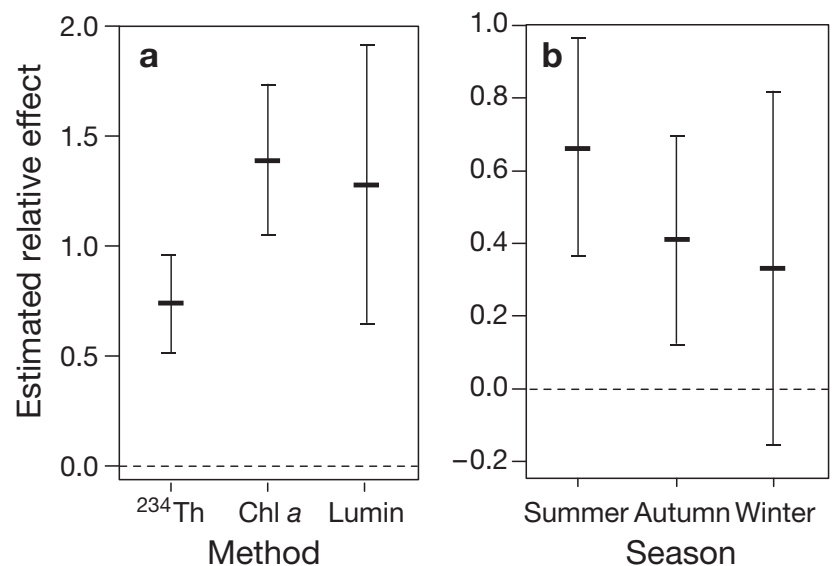

Fig. 4. Estimated relative effect of (a) method and (b) season for the global analysis of mixing intensity $\left(D_{\mathrm{b}}\right)$; (a) relative to ${ }^{210} \mathrm{~Pb}$ (dashed line); (b) relative to spring (dashed line). Error bars show $95 \%$ CI. Lumin: luminophores

\section{Temperate Northern Atlantic realm analysis}

$$
\text { Mixing depth }(L)
$$

The minimum adequate model for the analysis of mixing depth within the Temperate Northern Atlantic realm $(n=237)$ was a linear mixed effects model incorporating 3 single terms (method, season and water depth) and subregion as a random factor (L-ratio = $4.461, \mathrm{df}=1, \mathrm{p}=0.035)$. The maximal subset of data included 3 levels of method $\left({ }^{210} \mathrm{~Pb}\right.$, luminophores, SPI) and all seasons. Only season was required as a variance-covariate term. Method had the greatest influence on $L$ (L-ratio $=55.76, \mathrm{df}=2, \mathrm{p}<0.0001)$, followed by season (L-ratio $=16.79, \mathrm{df}=3, \mathrm{p}<0.0001$ ) and water depth (L-ratio $=6.91, \mathrm{df}=1, \mathrm{p}=0.009$ ). The data was not strong enough to investigate interactions between the single terms.

As with the global model, the depth of $L$ was dependent on the type of tracer used and the season in which the study was taken (Fig. 5). Closer examination of the model coefficients revealed that the inter-level differences in the values of $L$ for method and season were broadly consistent with the findings of the global model. Values of $L$ based on ${ }^{210} \mathrm{~Pb}$ were significantly higher than those estimated with SPI (coefficient $=0.678, \mathrm{df}=225, \mathrm{p}<0.0001$ ) and were marginally higher than those estimated with luminophores (coefficient $=0.389, \mathrm{df}=225, \mathrm{p}=0.055$; Fig. 5a). Estimates of $L$ based on luminophores are marginally higher than those based on SPI (coefficient $=0.368$, $\mathrm{df}=225, \mathrm{p}=0.044)$.

In terms of season, a pattern of estimated effect similar to the global model was predicted from the Temperate Northern Atlantic model (compare Figs. 3b \& 5b). The lowest values of $L$ occurred in the winter
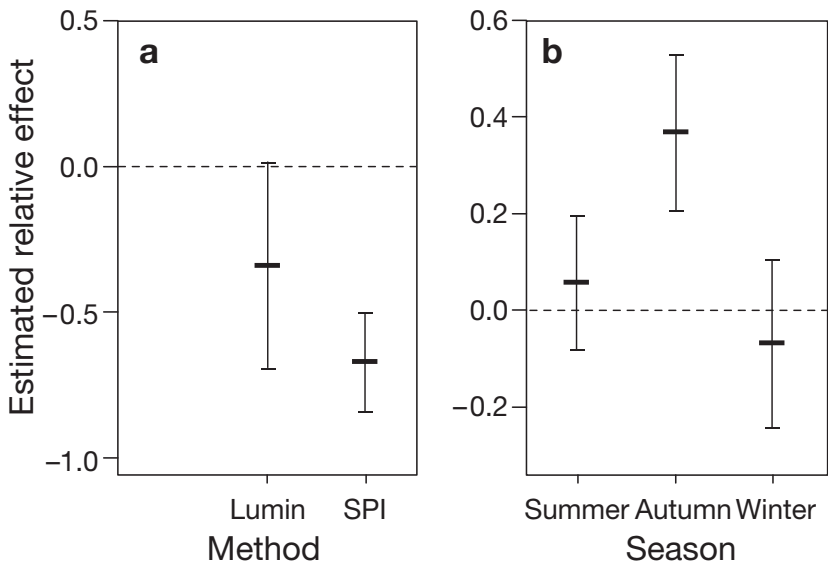

Fig. 5. Estimated relative effect of (a) method and (b) season on analysis of mixing depth $(L)$ in the Temperate Northern Atlantic realm; (a) relative to ${ }^{210} \mathrm{~Pb}$ (dashed line); (b) relative to spring (dashed line). Error bars show $95 \%$ CI. Lumin: luminophores 
and increased through the spring and summer before reaching a maximum in the autumn (Fig. 5b). Examination of the model coefficients revealed that values of $L$ measured in the autumn were significantly greater than those obtained in the spring (coefficient $=0.354$, $\mathrm{df}=225, \mathrm{p}=0.0001)$, summer (coefficient $=0.292, \mathrm{df}=$ $225, \mathrm{p}<0.001$ ) and winter (coefficient $=0.418, \mathrm{df}=225$, $\mathrm{p}=0.0001)$.

In contrast to the global analysis of $L$, water depth showed a positive effect on mixing depth (coefficient $=$ $\left.1.65 \times 10^{-4}, \mathrm{df}=225, \mathrm{p}=0.008\right)$, but as highlighted earlier, the ecological relevance of such a small effect is highly debatable and should be discounted.

\section{Bioturbation intensity $\left(D_{\mathrm{b}}\right)$}

The minimum adequate model for bioturbation intensity $\left(D_{\mathrm{b}}\right)$ within the Temperate Northern Atlantic realm $(\mathrm{n}=78)$ was a linear regression with a GLS extension incorporating 2 single terms (method and season). The maximal subset of data included 4 levels of method $\left({ }^{210} \mathrm{~Pb},{ }^{234} \mathrm{Th}\right.$, chl a, luminophores) and all seasons. There was no significant effect of region as a random factor (L-ratio $<0.0001, \mathrm{df}=1, \mathrm{p}=0.9999$ ), and the variance-covariate term was depth. Method had a greater influence on $D_{\mathrm{b}}$ (L-ratio $=31.93, \mathrm{df}=3, \mathrm{p}<$ 0.0001 ) than season (L-ratio $=18.47, \mathrm{df}=3, \mathrm{p}=0.0004$ ). As with the previous analyses, the data were not strong enough to investigate interactions between the single terms.

Overall, the patterns of $D_{\mathrm{b}}$ observed in the Temperate Northern Atlantic corresponded closely to those observed for the global analysis (Fig. 6), although there was less certainty in the results due to the reduction in data. Nevertheless, estimates of $D_{\mathrm{b}}$ determined using ${ }^{210} \mathrm{~Pb}$ were significantly lower than those based on chl a (coefficient $=-1.375, \mathrm{df}=$ $78, \mathrm{p}<0.0001$ ) and luminophores (coefficient $=$ -1.275 , df $=78, \mathrm{p}=0.001$ ), but not those based on ${ }^{234} \mathrm{Th}$ (coefficient $=-0.331$, df $=78, \mathrm{p}=0.08$ ) (Fig. 6a). Of the latter 3 methods, ${ }^{234} \mathrm{Th}$-based $D_{\mathrm{b}}$ values were significantly lower than those based on chl $a$ (coefficient $=-1.044, \mathrm{df}=78, \mathrm{p}<0.0001$ ) or luminophores (coefficient $=-0.944, \mathrm{df}=78, \mathrm{p}=$ 0.010). Chl $a$ and luminophore-based $D_{\mathrm{b}}$ values were equivalent to one another (coefficient $=0.099, \mathrm{df}=$ $78, \mathrm{p}=0.805$ ).

The highest $D_{\mathrm{b}}$ was recorded in summer, declining through autumn, winter and spring (Fig. 6b). However, the summer $D_{\mathrm{b}}$ values were only significantly higher than values obtained in the spring (coefficient $=0.838$, $\mathrm{df}=78, \mathrm{p}<0.0001$ ), a finding most likely due to the expanded confidence limits caused by the reduced dataset.
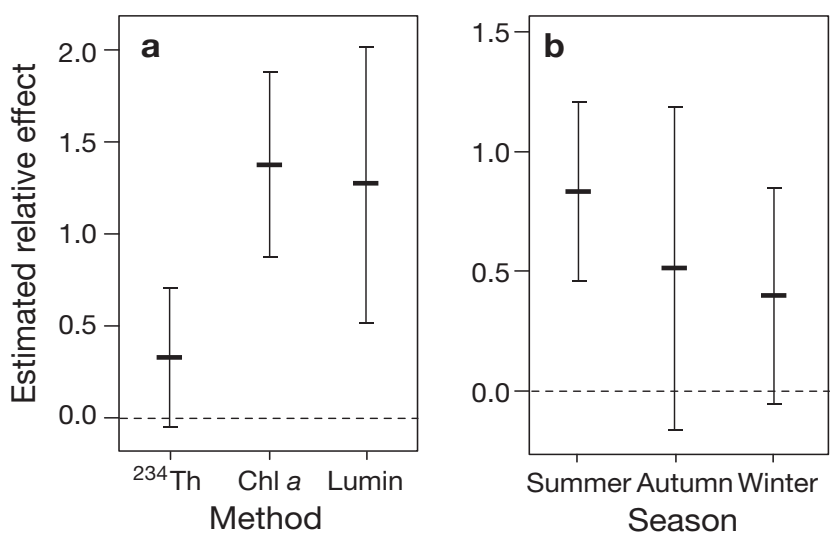

Fig. 6. Estimated relative effect of (a) method and (b) season on analysis of mixing intensity $\left(D_{\mathrm{b}}\right)$ in the Temperate Northern Atlantic realm; (a) relative to ${ }^{210} \mathrm{~Pb}$ (dashed line); (b) relative to spring (dashed line). Error bars show 95\% CI. Lumin: luminophores

\section{Regional patterns}

When comparing the global and Temperate Northern Atlantic realm analyses, broadly similar outcomes were determined for both $L$ and $D_{\mathrm{b}}$. We interpret this to indicate that the North Atlantic bias in the data governs the outcome of the global model, rather than suggesting that the same effects are dominant over different scales. The complex nature of the global and regional models for $L$ and $D_{\mathrm{b}}$, however, made it difficult to estimate patterns at a global level, although it was possible to determine relative differences using the raw data used within the models. In doing so, we found that the deepest values for $L$ were recorded in Temperate South America $(\bar{x}=6.4 \pm$ $2.7 \mathrm{~cm}, \mathrm{n}=10$ ), whilst the shallowest values of $L$ were located in the Temperate $(\bar{x}=0.8 \pm 1.8 \mathrm{~cm}, \mathrm{n}=5)$ and Polar $(\bar{x}=2.3 \pm 0.3 \mathrm{~cm}, \mathrm{n}=6)$ domains and in the Southern Ocean ( $\bar{x}=2.8 \pm 1.3 \mathrm{~cm}, \mathrm{n}=12)$. Bioturbation intensities follow the same pattern, with the highest mean $( \pm \mathrm{SD}) D_{\mathrm{b}}$ recorded in Temperate South America $(\bar{x}=$ $\left.35.90 \pm 40.78 \mathrm{~cm}^{2} \mathrm{yr}^{-1}, \mathrm{n}=7\right)$ and the lowest in the Temperate domain $\left(\bar{x}=0.8 \pm 2.3 \mathrm{~cm}^{2} \mathrm{yr}^{-1}, \mathrm{n}=12\right)$. It should be noted, however, that our formal analyses only identified significant effects of Region for $L$ and not for $D_{\mathrm{b}}$. Of the data used in the models, the Temperate Northern Atlantic realm had the highest number of datapoints for both $L(\mathrm{n}=256)$ and $D_{\mathrm{b}}(\mathrm{n}=87)$ and had a mean $( \pm \mathrm{SD})$ $L$ of $3.9 \pm 5.0 \mathrm{~cm}$ and $D_{\mathrm{b}}$ of $23.00 \pm 50.17 \mathrm{~cm}^{2} \mathrm{yr}^{-1}$.

Within the Temperate Northern Atlantic realm, the highest mean $( \pm \mathrm{SD}) L(\bar{x}=24.00 \pm 8.22 \mathrm{~cm}, \mathrm{n}=5)$ was observed in the Gulf of Maine, whilst the lowest was recorded in the Baltic Sea $(\bar{x}=0.9 \pm 0.7 \mathrm{~cm}, \mathrm{n}=40)$. The North Sea had the highest number of datapoints $(\mathrm{n}=135)$ and a mean $( \pm \mathrm{SD}) L$ of $2.7 \pm 2.3 \mathrm{~cm}$. The highest $D_{\mathrm{b}}\left(\bar{x}=59.01 \pm 86.85 \mathrm{~cm}^{2} \mathrm{yr}^{-1}, \mathrm{n}=21\right)$ was observed in the North Sea, whilst the lowest $D_{\mathrm{b}}(\bar{x}=1.7 \pm$ $3.4 \mathrm{~cm}^{2} \mathrm{yr}^{-1}, \mathrm{n}=5$ ) occurred in the Celtic Sea. 


\section{DISCUSSION}

A global database of bioturbation intensity and sediment mixing depths has been collated and analysed despite an inherent bias in the data and the inconsistencies between studies in recording information necessary for an integrative analysis. An important component missing from the dataset is information on the faunal assemblages dominant at the study sites, which is often poorly documented, absent, or focused on a particular species. The lack of information on faunal characteristics is not overly surprising as a large proportion of the studies in our database have a geological focus. Whilst data are numerous in areas that are either more accessible or near regions of high research density (e.g. Temperate Northern Atlantic realm), the Arctic, Central Pacific and most tropical regions lack sufficient data to make a credible position statement. Nevertheless, our results demonstrate broadly that methodology and season have clear effects on both $D_{\mathrm{b}}$ and $L$ and that water depth, although significant in our models, is unlikely to be of ecological importance over the range of depths so far studied $(<6000 \mathrm{~m})$.

Whilst our findings are consistent with previous, less statistically sophisticated analyses that used much smaller datasets (e.g. Boudreau 1994, 1998, Middelburg et al. 1997, Gerino et al. 1998), our analyses differ in that they fully incorporate the heteroscedasticity inherent in the data - caused by biogeographic regions using a mixed modelling framework. The inclusion of biogeographic regions in this way has revealed spatial differences in bioturbation at subregional and regional scales that have not been detected previously. Such regional differences contradict the view that a global average of $L$ is sufficient for sediment modelling purposes (Boudreau 1994), whilst reinforcing the argument that mixing depth reflects the supply and availability of food, rather than the activity of benthos per se (Trauth et al. 1997, Boudreau 1998, Smith \& Rabouille 2002, Niggerman et al. 2007; but see Johnson et al. 2007). The Temperate South American realm, for example, includes extremely productive areas of coastal upwelling and has both the deepest mixing depth and highest intensity of bioturbation (Gutierrez et al. 2000). In contrast, the Temperate domain includes a greater proportion of less productive waters and supports a low level of mixing intensity, with correspondingly shallow mixing depths.

Despite strong evidence for regional effects, there is little evidence for latitudinal or longitudinal effects on bioturbation. Intuitively, such trends are to be expected for both $L$ and $D_{\mathrm{b}}$, as both of these are linked to attributes of the fauna (species richness, biomass, abundance, functional groups) that vary along geographical clines (e.g. Rex et al. 2000, Roy et al. 2000,
Attrill et al. 2001, Cusson \& Bourget 2005, Ormond et al. 2005). Similar trends have also been documented with depth (e.g. Rex et al. 2006), but our data showed only weak evidence that $D_{\mathrm{b}}$ or $L$ follow suit. The lack of evidence for such trends is not, however, surprising given the limited quantity and sparse geographical spread of the available data.

Perhaps the most important findings of the present study are the large discrepancies in estimates of both $D_{\mathrm{b}}$ and $L$ between methods, raising critical questions over the validity and comparability of alternative techniques. Earlier studies (e.g. Smith et al. 1993, Pope et al. 1996, Gerino et al. 1998, Hughes et al. 2005) compared $D_{\mathrm{b}}$ coefficients obtained from different naturally occurring tracers within a specific region and, consistent with the findings presented here, concluded that the rates of bioturbation measured are commonly tracer dependent. For radionuclide tracers, for example, Smith et al. (1993) demonstrated that there is an inverse relationship between the half-life of the tracer used $\left({ }^{210} \mathrm{~Pb}\right.$, ${ }^{234} \mathrm{Th},{ }^{228} \mathrm{Th}$ and ${ }^{32} \mathrm{Si}$ ) and the observed mixing coefficient, indicating that the longer the period over which mixing effects are accumulated, the smaller the measured bioturbation intensity. Based on these findings, Smith et al. (1993) proposed that the characteristic time scale of a continuous-supply tracer (the time frame within which $95 \%$ of the tracer activity is likely to have entered deep-sea sediments) is approximately equal to 5 times its half-life. Thus, ${ }^{210} \mathrm{~Pb}$, which has a half-life of $22.3 \mathrm{yr}$, will record mixing events over $100 \mathrm{yr}$, whereas ${ }^{234} \mathrm{Th}$ (half-life of $24 \mathrm{~d}$ ) will illustrate mixing events over only $\sim 120 \mathrm{~d}$. There is, however, a more parsimonious explanation for the apparent tracer dependency observed between $D_{\mathrm{b}}$ values. The biodiffusion model is the default descriptor for biogenic reworking of sediments, but using such a model on short-lived radionucleotide profiles, or artificial tracers observed over a short duration (days), often violates the underlying assumptions of the model and will produce erroneous mixing coefficients (Reed et al. 2006). The relationship between $D_{\mathrm{b}}$ values and tracer half-life can, therefore, relate to use of the incorrect model, highlighting the unreliability of $D_{\mathrm{b}}$ values obtained from short-lived tracers.

The different time scales over which tracers operate will also affect the measured mixing depth, depending on how frequently deep mixing occurs and how fast a tracer decays relative to the rate and depth of mixing. Hughes et al. (2005) found that ${ }^{210} \mathrm{~Pb}$ estimates of $L$ in the Rockall Trough (NW of Scotland) were, on average, shallower than those measured by Thomson et al. (2000) using ${ }^{14} \mathrm{C}$ profiles at the same site. Unlike ${ }^{14} \mathrm{C}$, estimates of $L$ based on ${ }^{210} \mathrm{~Pb}$ also varied significantly within the site, indicating that ${ }^{14} \mathrm{C}$ (half-life of $5730 \mathrm{yr}$ ) was recording deep mixing events that occur infre- 
quently, perhaps only once in every 100 to $1000 \mathrm{yr}$. The discrepancy between ${ }^{14} \mathrm{C}$ and ${ }^{210} \mathrm{~Pb}$ has, however, been refuted by other studies that have obtained mixing depths that are in good agreement with one another and which approximate well to the sediment mixed layer (Nozaki et al. 1977, Peng \& Broecker 1979, Henderson et al. 1999). Model predictions from the analyses here show a similar discrepancy between ${ }^{210} \mathrm{~Pb}$ and ${ }^{234} \mathrm{Th}$, where deep mixing events occurring on greater time scales are more likely to be integrated using ${ }^{210} \mathrm{~Pb}$, resulting in deeper mixing depths. Shallower mixing depths can also be an artefact of tracer decay rate because, as is often the case when using ${ }^{234} \mathrm{Th}$, the tracer may disappear before reaching the mixing depth, especially in areas where deep mixing events occur frequently. Similarly, our analyses show that studies using other types of tracers (e.g. luminophores and chl a) that integrate over even shorter time scales (days) will generally result in higher $D_{\mathrm{b}}$ and shallower $L$. Whilst criticism over model selection may be valid in some cases (Reed et al. 2006), particles associated with chl $a_{1}$ for example, can also be affected substantially by the differential reworking of the sediment profile resulting from selective particle feeding. Particles that are low in excess density and/or have organic coatings (i.e. younger particles) are selected 10 to 100 times more often than surrounding sediment particles, increasing their mixing rate by the same order of magnitude (Smith et al. 1993). For some methods, however, particle displacement may be under-represented.

The low values of $L$ obtained using sediment profile imaging (relative to those obtained with particulate tracers) were a striking outcome of our analyses. In SPI images, the lower limit of mixing depth is delineated using colour, which correlates well with the transition between the oxic and anoxic layers of sediment (see e.g. Rosenberg et al. 2001, Diaz \& Trefy 2006) that is, in turn, influenced directly by infaunal bioturbation. Thus, being essentially biogeochemical profiles, SPI images are likely to reflect the rate of bioirrigation (and sediment permeability) rather than particle movement. Determining such a gradient can be a complex process, however, particularly in oligotrophic or deep areas where the colour change is less pronounced. Furthermore, differences in camera technology (e.g. sensor, colour response, flash position and intensity) and the sophistication of image analysis systems make direct comparisons between data obtained with different cameras difficult. Due to the different behaviour of tracers within the sediment and the discrepancy between mixing depths derived with SPI, methods used for assessing bioturbation intensities and sediment mixing depths need to be selected carefully based on their appropriateness for the objectives of the study, the processes in question and the time scales over which they operate. An equally cautious approach needs to be adopted when selecting models to fit the tracer profiles to ensure mixing coefficients are estimated appropriately (Reed et al. 2006).

Considering the characteristic time scales of some tracers, it is somewhat surprising to detect a strong effect of season on $L$ and $D_{\mathrm{b}}$. Had more data been available, it is likely that the inclusion of a method $x$ season interaction term in our models would have emphasized the importance of tracer dependency. This was not possible due to the dataset having a strong bias towards summer months and the low number of studies that provided a definitive study date. Nevertheless, seasonal differences are evident, and, although $L$ is not appreciably dependant on $D_{\mathrm{b}}$ (Boudreau 1994), there are many seasonal processes that would affect both $L$ and $D_{\mathrm{b}}$ simultaneously, such as plankton blooms and changes in species activity, abundance and biomass. Our analyses reveal a seasonally related change in $L$, but this lags behind that of $D_{\mathrm{b}}$ and may be affected more by seasonal increases in infaunal biomass or abundance that occur later in the year and lead to deeper burrowing events, than by bioturbation intensity per se.

Whilst its importance for habitat quality (Pearson \& Rosenberg 1978) and other ecosystem processes (e.g. Emmerson et al. 2001) is well known and has been well documented at local scales, bioturbation has seldom been considered on a global scale. Although we have assembled the most extensive database to date, significant gaps in our knowledge remain, hindering a derivation of global relations between variables that are needed to parameterize global diagenetic models of bioturbation. Taken as a whole, our analyses indicate a global mean $( \pm \mathrm{SD}) D_{\mathrm{b}}$ of $19.98 \pm 42.64 \mathrm{~cm}^{2} \mathrm{yr}^{-1}$ $(\mathrm{n}=454)$ and $L$ of $5.75 \pm 5.67 \mathrm{~cm}(\mathrm{n}=791)$. Based on a conservative estimate of ocean area of 360 million $\mathrm{km}^{2}$, the global volume of bioturbated sediment is $20700 \mathrm{~km}^{3}$, a quantity approximately 8.5 times the volume of Mount Everest or that would bury the entire metropolitan area of London under $13 \mathrm{~km}$ of sediment. Nevertheless, this estimate is small relative to the global mean $( \pm \mathrm{SD}) L$ of $9.7 \pm 4.5 \mathrm{~cm}(\mathrm{n}=200)$ calculated by Boudreau (1994). His estimate, however, did not include any measurements of $L$ by SPI, which underestimates particle movement and therefore lowers the global mean. Recalculation of $L$ for the present dataset reveals a global mixing depth of $2.52 \pm 2.46 \mathrm{~cm}$ ( $\mathrm{n}=381$ ) based on SPI or $8.37 \pm 6.19 \mathrm{~cm}(\mathrm{n}=403)$ based on particle tracer methods, raising the global estimate of bioturbated sediment to $30132 \mathrm{~km}^{3}$. Changes in bioturbation at this scale are likely to have far-reaching consequences for global cycles. Our focus was to provide a representative global estimate for sediments unaffected by human activity, but a large fraction 
$(41 \%)$ of the oceans have already been strongly affected by multiple anthropogenic drivers (Halpern et al. 2008). Comparison of the distribution of our datapoints with a global map of human impact on the world's oceans (loc. cit.) shows that much of our knowledge on bioturbation stems from areas that are most impacted. Given that the advent of complex bioturbation is one of the most significant events in the evolution of marine ecosystems (Seilacher \& Pflüger 1994), the question of how much the world's bioturbation has already been reduced and what effect any further loss may have on the function of the marine ecosystem remains an open empirical question.

Acknowledgements. The authors gratefully acknowledge K. E. Dyson, J. A. Godbold and L. M. Murray for their assistance with extracting data from the literature. We thank B. Boudreau (Dalhousie University, Canada), J. D. Germano (Germano and Associates, USA), R. J. Diaz (Virginia Institute of Marine Sciences, USA) and S. Creevan (Aquafact International, Ireland) for providing additional data, D. R. Green (University of Aberdeen, UK) for GIS guidance, R. G. Bailey (USDA Forest Service, USA) and M. Spalding (The Nature Conservancy, UK) for providing GIS shapefiles and 3 anonymous reviewers for helpful comments. This contribution is supported by a University of Aberdeen 6th Century scholarship (awarded to L.T.) and CEFAS, Lowestoft (DP204).

\section{LITERATURE CITED}

Attrill MJ, Stafford R, Rowden AA (2001) Latitudinal diversity patterns in estuarine tidal flats: indications of a global cline. Ecography 24:318-324

Bailey RG (1998) Ecoregions: the ecosystem geography of the oceans and continents. Springer, New York

Berg P, Rysgaard S, Funch P, Sejr MK (2001) Effects of bioturbation on solutes and solids in marine sediments. Aquat Microb Ecol 26:81-94

Blair NE, Levin LA, DeMaster DJ, Plaia G (1996) The shortterm fate of fresh algal carbon in continental slope sediments. Limnol Oceanogr 4:1208-1219

Boudreau B (1994) Is burial velocity a master parameter for bioturbation? Geochim Cosmochim Acta 58:1243-1249

Boudreau B (1998) Mean mixed depth of sediments: the wherefore and the why. Limnol Oceanogr 43:524-526

Crank J (1975) The mathematics of diffusion. Oxford University Press, Oxford

Cusson M, Bourget E (2005) Global patterns of macroinvertebrate production in marine benthic habitats. Mar Ecol Prog Ser 297:1-14

> Diaz RJ (2004) Biological and physical processes structuring deep-sea surface sediments in the Scotia and Weddell Seas, Antarctica. Deep-Sea Res II 51:1515-1532

Diaz RJ, Trefy JH (2006) Comparison of sediment profile image data with profiles of oxygen and Eh from sediment cores. J Mar Syst 62:164-172

Emmerson MC, Solan M, Emes C, Paterson DM, Raffaelli D (2001) Consistent patterns and the idiosyncratic effects of biodiversity in marine ecosystems. Nature 411:73-77

ETOPO2v2 (2006) 2-minute Gridded Global Relief Data (ETOPO2v2). US Department of Commerce, National Oceanic and Atmospheric Administration, National Geophysical Data Center. Available at: www.ngdc.noaa.gov/ mgg/fliers/06mgg01.html

Faraway JJ (2006) Extending the linear model with R. Generalized linear, mixed effects and non-parametric regression models. Chapman \& Hall/CRC and Taylor \& Francis Group, Boca Raton

Fenchel T (1969) The ecology of marine microbenthos. IV. Structure and function of the benthic ecosystem its chemical and physical factors and the microfauna communities with special reference to the ciliated protozoa. Ophelia 6:1-182

Forster S, Khalili A, Kitlar J (2003) Variation of nonlocal irrigation in a subtidal benthic community. J Mar Res 61: 335-357

Gerino M, Aller RC, Lee C, Cochran JK, Aller JY, Green MA, Hirschberg D (1998) Comparison of different tracers and methods used to quantify bioturbation during a spring bloom: 234-thorium, luminophores and chlorophyll a. Estuar Coast Shelf Sci 46:531-547

Green MA, Aller RC, Cochran JK, Lee C, Aller JY (2002) Bioturbation in shelf/slope sediments off Cape Hatteras, North Carolina: the use of ${ }^{234} \mathrm{Th}, \mathrm{Chl}-\mathrm{a}$, and $\mathrm{Br}^{-}$to evaluate rates of particle and solute transport. Deep-Sea Res II 49:4627-4644

Gutierrez D, Gallardo VA, Mayor S, Neira C and others (2000) Effects of dissolved oxygen and fresh organic matter on the bioturbation potential of macrofauna in sublittoral sediments off Central Chile during the 1997/1998 El Niño. Mar Ecol Prog Ser 202:81-99

Halpern BS, Walbridge S, Selkoe KA, Kappel CV and others (2008) A global map of human impact on marine ecosystems. Science 319:948-952

> Henderson GM, Lindsay FN, Slowey NC (1999) Variation in bioturbation with water depth on marine slopes: a study on the Little Bahamas Bank. Mar Geol 160:105-118

Howe JA, Shimmield TM, Diaz R (2004) Deep-water sedimentary environments of the northwestern Weddell Sea and South Sandwich Islands, Antarctica. Deep-Sea Res II 51:1489-1514

> Howe JA, Wilson CR, Shimmield TM, Diaz RJ, Carpenter LW (2007) Recent deep-water sedimentation, trace metal and radioisotope geochemistry across the Southern Ocean and northern Weddell Sea, Antarctica. Deep-Sea Res II 54: 1652-1681

Hughes DJ, Brown L, Cook GT, Cowie G and others (2005) The effects of megafaunal burrows on radiotracer profiles and organic composition in deep-sea sediments: preliminary results form two sites in the bathyal north-east Atlantic. Deep-Sea Res I 52:1-13

Johnson NA, Campbell JW, Moore TS, Rex MA, Etter RJ, McClain CR, Dowell MD (2007) The relationship between the standing stock of deep-sea macrobenthos and surface production in the western North Atlantic. Deep-Sea Res I 54:1350-1360

> Lovley DR, Phillips EJP (1986) Organic matter mineralisation with reduction of ferric iron in anaerobic sediments. Appl Environ Microbiol 51:683-689

Lyle M (1983) The brown-green colour transition in marine sediments: a marker of the Fe(III)-Fe(II) redox boundary. Limnol Oceanogr 28:1026-1033

Mahaut ML, Graf G (1987) A luminophore tracer technique for bioturbation studies. Oceanol Acta 10:323-328

- Meysman FJR, Boudreau B, Middelburg JJ (2003) Relations between local, non-local, discrete and continuous models of bioturbation. J Mar Res 61:391-410

Meysman FJR, Malyuga VS, Boudreau BP, Middelburg JJ (2008) Quantifying particle dispersal in aquatic sediments at short time scales: model selection. Aquat Biol 2:239-254 
Middelburg JJ, Soetaert K, Herman PKJ (1997) Empirical relationships for use in global diagenetic models. DeepSea Res I 44:327-344

Niggemann J, Ferdelman TG, Lomstein BA, Kallmeyer J, Schubert CJ (2007) How depositional conditions control input, composition, and degradation of organic matter in sediments from the Chilean coastal upwelling region. Geochim Cosmochim Acta 71:1513-1527

Nozaki YK, Cochran JK, Turekian KK, Keller G (1977) Radiocarbon and ${ }^{210} \mathrm{~Pb}$ distribution in submersible-taken deepsea cores from Project FAMOUS. Earth Planet Sci Lett 34:167-173

Ormond FGR, Gage JD, Angel MV (2005) Marine biodiversity. Patterns and processes. Cambridge University Press, Cambridge

Pearson TH, Rosenberg R (1978) Macrobenthic succession in relation to organic enrichment and pollution of the marine environment. Oceanogr Mar Biol Annu Rev 16:229-311

Peng TH, Broecker WS (1979) Rates of benthic mixing in deep-sea sediment as determined by radioactive tracers. Deep-Sea Res 11:141-149

Pinheiro JC, Bates DM (2000) Mixed-effects models in S and S-plus. Springer, New York

Pinheiro J, Bates D, DebRoy S, Sarkar D (2006) nlme: an R package for fitting and comparing Gaussian linear and nonlinear mixed-effects models. Available at: www.stats. bris.ac.uk/R/

Pope RH, DeMaster DJ, Smith CJ, Seltmann H Jr (1996) Rapid bioturbation in equatorial Pacific sediments: evidence from excess ${ }^{234} \mathrm{Th}$ measurements. Deep-Sea Res II 43: 1339-1364

R Development Core Team (2005) R: a language and environment for statistical computing. R Foundation for Statistical Computing, Vienna. Available at: www.R-project.org

Reed DC, Huang K, Boudreau BP, Meysmann FJR (2006) Steady-state tracer dynamics in a lattice-automaton model of bioturbation. Geochim Cosmochim Acta 70: 5855-5867

Rex MA, Stuart CT, Coyne G (2000) Latitudinal gradients of species richness in the deep-sea benthos of the North Atlantic. Proc Natl Acad Sci USA 97:4082-4085

Rex MA, Etter RJ, Morris JS, Crouse J and others (2006) Global bathymetric patterns of standing stock and body size in the deep-sea benthos. Mar Ecol Prog Ser 317:1-8

Rhoads DC, Cande S (1971) Sediment profile camera for in situ study of organism-sediment relations. Limnol Oceanogr 16:110-114

Submitted: January 3, 2008; Accepted: April 30, 2008
Rosenberg R, Nilsson HC, Diaz RJ (2001) Response of benthic fauna and changing sediment redox profiles over a hypoxic gradient. Estuar Coast Shelf Sci 53:343-350

Roy K, Jablonski D, Valentine JW (2000) Dissecting latitudinal diversity gradients: functional groups and clades of marine bivalves. Proc R Soc Lond B 267:293-299

> Sandnes J, Forbes T, Hansen R, Sandnes B, Rygg B (2000) Bioturbation and irrigation in natural sediments, described by animal-community parameters. Mar Ecol Prog Ser 197: 169-179

Seilacher A, Pflüger F (1994) From biomats to benthic agriculture: a biohistoric revolution. In: Krumbein WE, Paterson DM, Stal LJ (eds) Biostabilisation of sediments. Bibliotheks- und Informationssystem (BIS), Carl von Ossietzky Universität, Oldenburg

Smith CR, Rabouille C (2002) What controls the mixed-layer depth in deep-sea sediments? The importance of POC flux. Limnol Oceanogr 47:418-426

Smith CR, Pope RH, DeMaster DJ, Magaard L (1993) Agedependant mixing of deep-sea sediments. Geochim Cosmochim Acta 57:1473-1488

Solan M, Wigham BD, Hudson IR, Kennedy R and others (2004) In situ quantification of bioturbation using timelapse fluorescent sediment profile imaging (f-SPI), luminophore tracers and model simulation. Mar Ecol Prog Ser 271:1-12

Spalding M, Fox H, Davidson N, Ferdana Z and others (2007) Marine ecoregions of the world: a bioregionalization of coast and shelf areas. Bioscience 57:573-583

- Thomson J, Brown L, Nixon S, Cook GT, MacKenzie AB (2000) Bioturbation and holocene sediment accumulation fluxes in the north-east Atlantic (Benthic Boundary Layer Experiment sites). Mar Geol 169:21-39

> Trauth MH, Sarnthein M, Arnold M (1997) Bioturbational mixing depth and carbon flux at the seafloor. Paleoceanography 12:517-526

West BT, Welch KB, Galecki AT (2007) Linear mixed models. A practical guide using statistical software. Chapman \& Hall, New York

Wheatcroft RA, Olmez I, Pink FX (1994) Particle bioturbation in Massachusetts Bay: preliminary results using a new deliberate tracer technique. J Mar Res 52:1129-1150

Yang HS, Nozaki Y, Sakai H, Nagaya Y, Nakamura K (1986) Natural and man-made radionuclide distributions in northwest Pacific deep-sea sediments: rates of sedimentation, bioturbation and ${ }^{226} \mathrm{Ra}$ migration. Geochem J 20: 29-40

Proofs received from author(s): June 2, 2008 